\title{
Beyond Public Health Emergency Legal Preparedness: Rethinking Best Practices
}

\author{
Jennifer A. Bernstein
}

I $t$ has now been 10 years since the framework for public health legal preparedness was put forth as a model to meet new public health challenges in the 21st century. ${ }^{1}$ Public health legal preparedness is defined as the "attainment by a public health system of specified legal of standards essential to the preparedness of the public health system."2 The framework has continued to develop over time and four core elements have emerged to make up the basis for public health legal preparedness. The four core elements are: (1) laws and legal authorities; (2) competency in using laws effectively and wisely; (3) coordination of legally based interventions across jurisdictions and sectors; and (4) information on public health laws and best practices. ${ }^{3}$ In this article, I will discuss the need to refocus public health legal preparedness to include all areas of public health law and present a new model for the fourth core element that will aid in the development of legal benchmarks so public health systems can more effectively work towards attaining public health legal preparedness in all areas of public health practice.

\section{Public Health Legal Preparedness, Not Public Health Emergency Legal Preparedness}

The framework was developed broadly to be utilized to achieve full public health legal preparedness for all areas of public health law. Anthony Moulton et al. stressed that legal preparedness is more expansive than just public health emergencies by stating, "...the

Jennifer A. Bernstein, J.D., M.P.H., is a Staff Attorney at the Network for Public Health Law Mid-States Region at the University of Michigan School of Public Health in Ann Arbor, MI. She holds a J.D. and an M.P.H from the University of Iowa and a B.S. from the University of Wisconsin-Madison. larger goal should be full legal preparedness for all types of dangers to the health of the public...many of which individually account for greater morbidity and mortality than do public health emergencies in the aggregate."

But somewhere along the line, public health legal preparedness became synonymous with public health emergency legal preparedness. ${ }^{5}$ Though the concept of public health legal preparedness grew out of the emergency preparedness movement, ${ }^{6}$ it must be inclusive of more than just emergencies to become a useful tool in furthering the use of law to protect the public's health.

Through my work advising public health attorneys and practitioners, I have seen a strong desire for functional tools that allow attorneys and practitioners to understand and effectively apply the law to solve everyday public health problems. Public health attorneys and practitioners want comprehensive summaries of state and local public health laws, procedural guidelines, compilations of jurisdictionally appropriate opinions interpreting public health laws, and checklists to ensure compliance. These tools can and should be developed for all areas of public health law, not just public health emergency law, to ensure that state and local public health departments are adequately prepared to deal with all types of dangers to the public's health.

\section{Preparedness as Public Health Legal Practice}

After conducting a workshop in the spring of 2012 with a group of attorneys and health officers serving local public health departments (LHDs) in Indiana on the topic of public health legal preparedness, I realized that a division exists. There is a division between 
public health law theorists and public health law practitioners - practitioners do not have time to ponder about the intricacies of public health legal theory. The breadth of legal issues and the types of laws that attorneys dealing with local public health challenges must be familiar with is extensive. Also, attorneys who represent LHDs usually have many competing priorities for their time and resources, since they often serve as the attorney not just to the local public health department, but to the county as a whole. This leaves little time for deep reflection on legal theory or the attainment of the degree of specialized legal knowledge that is truly required for public health legal preparedness. best practice within public health law? Who decides what constitutes a best practice? One definition for public health law best practice is "[the] application of the pertinent legal authorities by officials competent in their use and with coordination across the relevant jurisdictions and sectors."? This definition seems to simply combine the first three elements of legal preparedness together and does not add to the overall effective application of the framework.

The fourth element needs to be reengineered to better serve the goal of full legal preparedness for all areas of public health law. Best practice implies an all or nothing approach - without the best pos-

The legal preparedness framework has not been defined or applied adequately to the point where it can be a useful tool for legal practitioners and have the greatest impact on public health law practice. For public health legal preparedness to be viable outside the context of emergency legal preparedness, the public health law community must develop practical tools to aid in the establishment of legal benchmarks in all areas of public health law practice.

The goal of public health legal preparedness is to include the attainment of legal benchmarks by public health systems to ensure legal preparedness in all areas. Outside the area of public health emergency preparedness, there are few, if any, legal benchmarks for attorneys to attain public health legal preparedness. The practice of public health law, especially at the local level, would greatly benefit from more resources to guide practitioners in the effective use and application of the law. This is the key role of legal preparedness: to guide the day-to-day work of legal counsel and public health practitioners at the local level.

What would it mean to be legally prepared in injury prevention? What should legal benchmarks look like to achieve legal preparedness when faced with the clean up of a meth lab? The legal preparedness framework has not been defined or applied adequately to the point where it can be a useful tool for legal practitioners and have the greatest impact on public health law practice. For public health legal preparedness to be viable outside the context of emergency legal preparedness, the public health law community must develop practical tools to aid in the establishment of legal benchmarks in all areas of public health law practice.

\section{Rethinking Best Practice}

When preparing for the Indiana workshop, I was most concerned by the fourth element: information on public health laws and best practices. What exactly is a sible evidence, practitioners cannot move forward in the development of a best practice which guides that area of public health. ${ }^{8}$ To be a practical tool for public health legal practice, the public health law community should be more concerned with using the best available evidence, not the best possible evidence. Best practice also suggests no need to add to the existing base of knowledge or disseminate lessons learned through the practice of public health law, because we would already be engaging in the optimal mode of practice.

The fourth element should instead be focused on evidence and experience based public health law practice. Evidence- and experience-based public health law practice is the effective use of legal-based efforts to improve public health through identification, assessment, implementation, and monitoring and evaluation of the best available scientific and legal public health information.

The goal of evidence- and experience-based public health law practice is to provide a recursive process that continually adds to the existing body of public health law knowledge to support the development of future public health laws and legal practice. This is accomplished through four steps:

- Identification

Identify relevant experiential information and research on specific legal-based efforts that 
are likely to be effective for the targeted public health challenge.

\section{- Assessment}

Assess resources and evidence to determine their strength and identify any need for adaptation, given the specific characteristics of the jurisdiction for which the intervention will be applied.

\section{- Implementation}

Develop an action plan to implement the targeted legal intervention, identifying key stakeholders or partners that are essential or helpful in implementation.

\section{- Monitoring and Evaluation}

Develop, by attorneys, practitioners, and researchers, a record of successful practices or research findings on the effectiveness of the legal intervention to inform future action and increase the public health law knowledge base.

\section{Importance of Experiential Knowledge}

Work by governmental, academic, and nonprofit organizations provides research and resources to public health attorneys and practitioners. For the 18 states that have developed public health law bench books through guidance by the Centers for Disease Control and Prevention's Public Health Law Program, they represent an invaluable tool to attorneys and practitioners. ${ }^{9}$ The Network for Public Health Law develops practical legal tools - many specific to individual states or local jurisdictions - that are focused on a myriad of public health law problems..$^{10}$ Public Health Law Research helps build the evidence base for the effectiveness of public health laws, especially on the state and federal level. ${ }^{11}$

Yet legal public health preparedness must go beyond the examination of existing or future law and should not be used as a model only for the justification of legislative or regulatory changes. Public health legal preparedness must support immediate public health action and program planning based on existing public health law and knowledge. It is imperative to consider the day-to-day practice of local public health attorneys and public health practitioners who use law to carry out public health objectives. Therefore, it is important to base public health legal preparedness not just on peer-reviewed research, but also on experiential knowledge developed through the actual practice of public health law.

In order to build a base of experiential knowledge, public health attorneys and practitioners must be provided with a mechanism to compile, evaluate, and share information not only within their own agencies, but with the larger public health community. ${ }^{12}$ A shared base of experiential knowledge will provide public health attorneys with more resources to develop the degree of specialized legal knowledge that is truly required for attainment of public health legal preparedness in all areas of public health law. An open platform to share experiential knowledge between public health attorneys and practitioners, in the form of an online database and forum, will provide a place for information that seldom appears in journal articles or legal treatises, such as individual case studies, failures, and lessons learned. The opportunity to provide peer assistance can elevate collaboration between attorneys without access to an existing network of peer mentors. The combination of evidence-based and experiential public health law practice information will aid in the development of legal benchmarks so public health can work towards legal preparedness in all areas of public health law practice.

\section{Conclusion}

The work that has been achieved around public health emergency legal preparedness has helped tremendously to elevate the importance of public health law as a distinct and essential legal discipline. But it is now time to expand beyond emergencies and advance public health legal preparedness for the larger field of public health law as a guide to enhancing public health legal practice in all areas. Through reengineering of the fourth element of public health legal preparedness, the public health community can work towards a more robust knowledge base to aid in the attainment of legal benchmarks by public health systems to ensure legal preparedness in all areas of public health practice.

\section{References}

1. A. D. Moulton, R. A. Goodman, K. Cahill, and E. L. Baker, Jr., "Public Health Legal Preparedness for the 21st Century," Journal of Law, Medicine E Ethics 30, no. 2 (2002): 141-143.

2. A. D. Moulton, R. N. Gottfried, R. A. Goodman, A. M. Murphy, and R. D. Rawson, "What Is Public Health Legal Preparedness?” Journal of Law, Medicine छீ Ethics 31, no. 4 (2003): $672-683$, at 674 .

3. G. C. Benjamin and A. D. Moulton, "Public Health Legal Preparedness: A Framework for Action," Journal of Law, Medicine छै Ethics 36, no. 1 (2008): 13-17.

4. See Moulton et al., supra note 2, at 672 .

5. Moulton et al. detailed efforts in public health legal preparedness with respect to massive public health emergencies. Id., at 680-681. Four years later, in June 2007, the first National Summit on Public Health Legal Preparedness was convened and a related Journal of Law, Medicine and Ethics special symposium issue detailed the proceedings, which related solely to public health emergency legal preparedness topics. See M. M. Ransom, W. Lopez, R. A. Goodman, and A. D. Moulton, eds., "The National Action Agenda for Public Health Lega Preparedness" Journal of Law, Medicine and Ethics 36, no. 
1 (2008): 1-80. One notable exception is the National Summit on Legal Preparedness for Obesity Prevention and Control and the related Journal of Law, Medicine and Ethics special symposium issue. See D. E. Benken, M. A. Reynolds, and A. S. Hunter, eds., "Proceedings of the National Summit on Legal Preparedness for Obesity Prevention and Control," Journal of Law, Medicine and Ethics 37, no. 2 (2009): 1-151.

6. See Moulton et al., supra note 2, at 672.

7. See Benjamin and Moulton, supra note 3, at 16.

8. R. C. Brownson, J. E. Fielding, and C. M. Maylahn, "EvidenceBased Public Health: A Fundamental Concept for Public Health Practice," Annual Review of Public Health 30 (2009): 175-201, at 177-178.

9. See Centers for Disease Control and Prevention Public Health Law Program, Public Health Law Bench Books, available at $<$ http://www.cdc.gov/phlp/publications/type/benchbooks. html> (last visited January 4, 2013).
10. For more information about The Network for Public Health Law and to view Network resources, visit <http://www.networkforphl.org> (last visited January 4, 2013).

11. For more information about Public Health Law Research, visit $<$ http://publichealthlawresearch.org/> (last visited January 4, 2013). See also, S. Burris, A. C. Wagenaar, J. Swanson, J. K. Ibrahim, J. Wood, and M. M. Mello, "Making the Case for Laws That Improve Health: A Framework for Public Health Law Research," The Milbank Quarterly 88, no. 2 (2010): 169-210.

12. Though the idea of a public health law collaborative to allow interaction between elected officials, public health practitioners, attorneys, researchers, and educators was envisioned at the inception of public health legal preparedness, more work needs to be done to ensure access to a forum for the exchange of experiential information and expanded opportunities for collaboration. See Moulton et al., supra note 1, at 143. 